\title{
La herencia de las Sententiae de Publilio Siro en las paremias españolas en torno a la avaricia
}

\author{
Reception of Publilius Syrus' Sententiae \\ in Spanish proverbs on greed
}

\author{
Xavier Pascual-López \\ Uniwersytet im. Adama Mickiewicza, Poznań \\ xavpas@amu.edu.pl
}

\begin{abstract}
The aim of this paper is to present the Spanish proverbs related to the topic of greed that can be understood as a continuation of Publilius Syrus' sentences. For the analysis are taken into account the contributions of two Hellenistic philosophical schools (Stoicism and Epicureanism), which illuminate the scope of the criticism of greed that occurs in these proverbs, both from a psychological as a social point of view. Latin sentences and Spanish proverbs are compared according to their formal or semantic continuity, as well as depending on other aspects (such as the tone or prosodic issues).
\end{abstract}

Keywords: paremiology, Spanish proverbs, Publilius Syrus' sentences, greed, stoicism, epicureanism

\section{INTRODUCCIÓN}

Es frecuente oír que los refranes ${ }^{1}$ conforman un compendio de sabiduría popular que emana de la experiencia de los antepasados, los cuales intentaron dar sentido al

\footnotetext{
${ }^{1}$ En el presente artículo usaremos la siguiente terminología: el término paremia será entendido de forma general como enunciado fraseológico con significado referencial y autonomía textual (Corpas Pastor 1996: 132-133); de forma más específica se empleará refrán como el tipo de paremia por excelencia: de origen popular, de autoría anónima, con valor de verdad general y que responde a una serie de características formales (Corpas Pastor 1996: 148); en cambio, reservamos el término sentencia para paremias cultas, de autor habitualmente conocido (en nuestro caso de origen clásico). En cuanto
} 
mundo que les rodeaba, de modo que el refranero se instituye como un código de conducta para las nuevas generaciones. Pese a que normalmente se considera que los refranes son populares y de origen desconocido, no hay que pasar por alto que muchos de ellos se inscriben en tradiciones textuales que se remontan a la tradición judeocristiana, a la cultura grecorromana o al mundo árabe (Sevilla \& Cantera 2002: 29-78). En las tres tradiciones existieron y circularon compilaciones de paremias atribuidas a varios sabios, las cuales a su vez pudieron ser adoptadas por la tradición popular mediante la cristalización de refranes. Una de las colecciones de sentencias más conocidas fueron las Sententiae del mimógrafo Publilio Siro, recopiladas ya en la Antigüedad y empleadas con variaciones durante la Edad Media en el ámbito escolar, a menudo integradas en los Proverbia Senecae (Giancotti 1963; Round 1972: 103-104). A causa de la difusión y la popularidad de este repertorio de sentencias, no es de extrañar que las lenguas europeas las hayan adaptado. Por ello, el objetivo de este artículo es rastrear la pervivencia de algunas de las sentencias de Siro entre las paremias españolas, en concreto aquellas que giran en torno al tema de la avaricia.

A pesar de que estas sentencias se incluyen en tradiciones textuales mucho más extensas, en estas páginas centraremos el análisis en la concordancia o no de estas paremias respecto a los presupuestos de las dos escuelas filosóficas helenísticas de mayor trascendencia: el estoicismo y el epicureísmo. Aunque suelen presentarse como doctrinas antagónicas, en el fondo tienen aspectos en común, como el hecho de dar absoluta preeminencia a la ética, puesto que todo en su filosofía queda subordinado al proyecto vital de alcanzar el bienestar y la felicidad (Cardona 2015: 21); y una de las pasiones que - según ambas escuelas - el ser humano tendrá que superar es la avaricia, por lo que su trascendencia para el tema que nos ocupa es evidente. Asimismo, la pertinencia de esta perspectiva de estudio viene reforzada por el hecho de que las sentencias de Siro fueran incluidas e incluso atribuidas a Séneca, referente del estoicismo en el ámbito hispano.

\section{LA NATURALEZA DEL AVARO}

La consideración de la avaricia como un mal en sí mismo es un lugar común que impregna diferentes tradiciones. Se encuentra tanto en el Antiguo como en el Nuevo Testamento (Si. 10.9, 1Tim. 6.10) y recorre la literatura clásica ${ }^{2}$.

\footnotetext{
a otros términos (p. ej. máxima), se utilizarán cuando la tradición los haya empleado de forma sistemática. En su gran mayoría, las paremias españolas se han extraído del refranero de Martínez Kleiser (1953) y se citan acompañadas de su numeración dentro de esta obra (excepto cuando se indique una fuente distinta).

${ }^{2}$ Es imposible citar aquí todos los pasajes en los que se recurre a esta idea, por ej. Ex avaritia (...) omnia scelera ac maleficia gignuntur ('De la avaricia nacen todos los crímenes y malas acciones'. Cic. Rosc. Amer. 27.75). Todas las traducciones de las paremias y citas latinas son nuestras.
} 
El estoicismo y el epicureísmo comparten la idea de que la avaricia es un obstáculo para la consecución de la felicidad, pero por diferentes razones. Para los estoicos, el afán de posesiones es una pasión que impide que el ser humano se rija de acuerdo con la razón, por lo que debe evitarse o controlarse (Cardona 2015: 67), hasta tal punto que el monje de raigambre estoica del siglo IV Evagrio Póntico (Tract. pract. 6, Cap. Cogn. 7) incluye la avaricia dentro de los ocho pensamientos que acechan al ser humano, imaginándola - siguiendo 1Tim. 6.10 - como la raíz de todos los males, ya que de su control depende el de otras emociones negativas (la ira, la depresión, el orgullo...) (Sorabji 2000: 358-359, 364-365). Por su parte, los epicúreos consideran que esta ansia sobrepasa los límites de la naturaleza, produce turbación del alma, siendo fuente de miedo y dolor, debido a lo cual impide la realización del placer que llevaría a la dicha (Oyarzún 1999: 419).

En las paremias, la actitud negativa hacia la avaricia se concreta de dos maneras: extrínseca (criticándose desde el punto de vista de la comunidad, centrándose en su efecto en la sociedad) o intrínsecamente (enfocándose en el impacto en la psique de quien la padece). La censura extrínseca no se corresponde con los presupuestos estoicos ni epicúreos, pues para ambos la avaricia es indeseable por las consecuencias que tiene para quien la sufre, dado que el ansia de querer más le genera una perturbación del ánimo que lo aleja de los ideales de la felicidad ${ }^{3}$.

La idea de la negatividad intrínseca de la avaricia se encuentra en dos sentencias de Siro: Avarus ipse miseriae causa est suae ('El mismo avaro es la causa de su propia miseria', $\mathrm{A} 14^{4}$ ), Avaro acerba poena natura est sua ('Para el avaro su propia naturaleza es un cruel castigo', A46). Este tipo de censura psicológica es poco productiva en el acervo paremiológico español; no obstante, Sbarbi (1943: 105) recoge la paremia No hay avaricia sin pena, que se corresponde con la segunda sentencia citada.

De forma similar, la sentencia Avaro non est vita, sed mors longior ('El avaro no tiene vida, sino una muerte más larga', A47) hace hincapié en el perjuicio que el avaro sufre debido a su naturaleza. Como consecuencia de esta "muerte en vida", otra sentencia se pregunta: Avaro quid mali optes nisi vivat diu? "¿Qué mal le deseas al avaro sino que viva largo tiempo?', A26). Cambiando la modalidad interrogativa por la exhortativa, la paremia $\mathrm{Al}$ avaro no le desees más mal que la vida (5915) sigue claramente esta última sentencia. Sin embargo, igual que en el caso anterior, los equivalentes españoles son muy limitados.

Esta escasez de paremias puede entenderse a la luz de dos hechos. En primer lugar, tal como veremos a continuación, en el refranero el tema de la avaricia suele

\footnotetext{
${ }^{3}$ En la Carta a Meneceo (128) de Epicuro leemos que hay que "condicionar toda elección y repulsa a la salud del cuerpo y a la imperturbabilidad del ama, ya que éste es el fin de una vida dichosa. Pues todo lo que hacemos lo hacemos por esto, para no sentir dolor ni temor" (Vara 1999: 89).

${ }^{4}$ Seguimos la lectura y numeración canónica de Meyer (1880).
} 
tratarse más bien desde la mencionada perspectiva extrínseca. Y en segundo lugar, el refranero tiende a tratar este tema con un tono jocoso, ridiculizando la actitud y el comportamiento de los avaros, o sea, recurriendo a la sátira como correctivo, como si siguiera la conocida sentencia Castigat ridendo mores ('Corrige riendo las costumbres', Sánchez Doncel 2003).

\section{EL IMPACTO DEL AVARO EN LA COMUNIDAD}

A medio camino entre la crítica intrínseca y la extrínseca, la sentencia In nullum avarus bonus est, in se pessimus ('Para nadie el avaro es bueno; para sí mismo, pésimo', I5) cuenta con un equivalente literal (Para nadie es bueno el avaro, y para sí muy malo, 5934) y otro con variación adjetival (El avariento, para sí es malo y para nadie es bueno, 5933). Esta sentencia pone de relieve cómo el avaro falta a la idea de bien, no solo en un sentido social sino especialmente en un sentido individual (de acuerdo con la postura helenística), pero de nuevo vemos que es poco productiva en nuestro refranero.

En cambio, adopta una perspectiva social la sentencia Avarus nisi cum moritur, nihil recte facit ('El avaro no hace nada bien, sino cuando se muere', A23), que recalca que el egoísmo del avaro dura hasta su muerte, a la cual sus herederos se harán con lo que no les dio en vida ${ }^{5}$. El equivalente español más literal es Del avaro un solo bien se espera: que se muera (5994). Otros verbalizan en qué consiste este "bien", es decir, los bienes de los que se desprenderá (Hombre avaricioso, solo en la muerte es generoso; Porque llevártelo no pudiste, al morir lo diste, 5990-1; Dan limosna muertos los que vivos no la dieron, 36717). No obstante, la versión más conocida de esta sentencia es la que asocia de forma jocosa y disfemística al avaro con el cerdo, pues ambos resultan exclusivamente "útiles" a su muerte (El avariento, todo lo da junto, como el puerco, 5986; El avariento y el puerco, después de muertos, 5988; cf. 5985-94). El gran número de variaciones sobre esta asociación es una muestra de la extensión y la aceptación de la paremia, que también cuenta con versiones en las que el rico sustituye al avaro, puesto que en la mentalidad popular son características que suelen vincularse (El rico y el cochino más sirven muertos que vivos, 56186; El rico y el cochino no aprovechan vivos; pero cuando muertos están, iqué ratos tan buenos dan!, 56187).

El egoísmo del avaro es también el tema de Negandi causa avarum nunquam deficit ('Al avaro nunca le falta un motivo para negarse', N10). La misma idea se

\footnotetext{
${ }^{5}$ Por tanto, se niega la eventualidad de una enmienda moral por parte de quien se ve aquejado de avaricia. Mientras el estoicismo estricto (p. ej. Crisipo) habría concordado con este extremismo, muchos estoicos posteriores afirmaron que el sabio se esfuerza por aprender de sus errores y mejorar su situación, por lo que está sujeto a un proceso de perfeccionamiento moral (Cardona 2015: 66), la posibilidad del cual vendría refutada por la sentencia.
} 
reproduce en diversas paremias españolas, en las que el tono socarrón es evidente: se presenta irónicamente la incredulidad ante la supuesta generosidad de un avaro (¿Avaro y da? De lo ajeno será; ¿Avaro y expendiendo? No lo entiendo, 5885-6), se reproducen polifónicamente las palabras del avaro que se niega a dar (Dice al pobre el avaro: "Ayúdete Dios, hermano", 5889; Pídeme el alma, pero la bolsa, ni en chanza, 5899), porque la creencia es que el avaro nunca cambia (El avaro dará un maravedi de sus bienes la semana que no tenga viernes, 5887; Del avariento, ni un pimiento, 5897), pues solo será posible que dé algo bajo coacción (Al avaro, danle en el codo para que abra la mano, 5894). Por el contrario, se elogia la generosidad de las personas desprendidas en paremias cuyo tono es claramente mucho más solemne (Al liberal, nunca le falta qué dar; El liberal busca ocasiones para dar, 36457-8).

\section{LA AVARICIA COMO EXCESO INMODERADO}

Ambas doctrinas helenísticas critican la avaricia por ser un vicio por exceso. El sabio estoico, gracias al conocimiento del cosmos como un todo ordenado por la razón, tiene la capacidad de ajustar sus deseos a lo posible y verosímil dentro de ese universo, de manera que se sirve de la razón para regirse con moderación (Martos Montiel 1998: 201; Sellars 2006: 51). A su vez, el sabio epicúreo combate el acecho de las pasiones (p. ej. el afán de gloria o de posesiones) usando la razón para restringirlas a los límites impuestos por la naturaleza, entendiendo que hay que acostumbrarse a la escasez para poder disfrutar de una eventual y temporal abundancia sin que se socave la tranquilidad del alma (i. e. sin envanecerse ni tener miedo a perder lo conseguido), por lo que la moderación es deseable en cuanto permite dejar de lado los placeres que entrañan un dolor ulterior (Oyarzún 1999: 419; García Gual 2003: 27; Long 2005 [1984]: 75).

A tenor de estas consideraciones hay que interpretar la sentencia Tam deest avaro quod habet, quam quod non habet ('Al avaro le falta tanto lo que tiene como lo que no tiene', T3), pues la falta de moderación lleva a un perpetuo anhelo y al desasosiego vital. Los compendios paremiológicos españoles recogen diferentes adaptaciones prácticamente literales (El avariento tanto está falto de lo que tiene como de lo que no tiene, 5925, cf. 5924), así como otras un poco más libres (El avaro, por gastar poco, aunque todo lo tiene, carece de todo, 5926; cf. 5927) ${ }^{6}$.

En la misma línea encontramos otra sentencia publiliana: Inopiae desunt multa, avaritiae omnia ('A la pobreza le falta mucho, a la avaricia todo', I7) ${ }^{7}$, que en

\footnotetext{
${ }^{6}$ Entre las sentencias apócrifamente atribuidas a Siro leemos lo que podría ser una glosa que explica la sentencia anterior: Pecunia non satiat avarum, sed irritat ('El dinero no sacia al avaro, sino que lo estimula', Ps.Pub. 286). En realidad estas sentencias podrían englobarse dentro del tópico que Séneca (Ep. 119.6) formuló como Qui multum habet, plus cupit ('Quien tiene mucho, desea más').

${ }^{7}$ Esta sentencia es citada por Séneca (Ep. 108.9) como una máxima muy conocida, usada en el teatro y ante la cual todos los espectadores asienten por entenderla como una verdad universal.
} 
español se ha adaptado de forma más bien artificialmente literal (La pobreza carece de muchas cosas; la avaricia, de todas, 5928), aunque también intentando darle una formulación más acorde con las características prosódicas del refrán (Al pobre le falta un poco; al avaro, todo, 5929).

Por último, una tercera sentencia insiste en esta misma concepción: Instructa inopia est in divitiis cupiditas ('La ambición en la riqueza es una pobreza bien provista', I8), que cuenta con La avaricia es suma pobreza en el que codicia (5923) como equivalente español.

Además de estas tres, también se han atribuido a Siro dos sentencias que proclaman la eterna pobreza (e insatisfacción) a la que condena la avaricia: Avarus animus nullo saciatur lucro ('El espíritu avaro no se sacia con ganancia alguna', Ps.Pub. 36); Avidissimus quisque est egestosissimus ('Quien es muy avaricioso es muy pobre', Ps.Pub. 42) ${ }^{9}$. En español se registra alguna paremia formalmente poco elaborada (No hay tal pobre como el avariento, 5931; Siempre es pobre el codicioso, 11267), y otras en las que se recurre a elementos estilísticos que refuerzan su proverbialidad (El avariento, no es más pobre con uno que con ciento, 5913; El avariento siempre está sediento, 5966).

\section{EL IDEAL DE AUSTERIDAD}

En consecuencia, la avaricia conduce a la infelicidad, lo cual contraviene la aspiración de los sabios helenísticos. A la perturbadora insaciabilidad de la avaricia, ambas escuelas imponen un ideal de austeridad basado en la autarquía, en una autosuficiencia centrada en lo humano que será la clave para la consecución de la felicidad. Este giro hacia el interior del ser humano es clave para entender la misión de estas doctrinas, por lo que se comprende que sus ideas lleguen a impregnar las paremias, cuya función suele ser erigirse en un modelo de conducta.

En sí misma la riqueza no es un mal ni para los estoicos ni para los epicúreos. Para los primeros, es preferible a la pobreza, aunque ambas son moralmente indiferentes (Long 2005 [1984]: 188-189; Cardona 2015: 65-66); para los segundos, es algo de lo que puede disfrutarse siempre y cuando uno se haya ejercitado en la

\footnotetext{
${ }^{8}$ A su vez, estas paremias hay que relacionarlas con otra sentencia de mayor alcance semántico, en la que se proclama que la fortuna nunca da suficiente a nadie: Fortuna multis dat nimis, satis nulli ('La fortuna a muchos da demasiado, pero a nadie bastante', Mart. 12.10.2).

${ }^{9}$ En realidad, estas sentencias apócrifas son poco conocidas, mientras que a menudo se cita y se repite la formulación que Horacio (Ep. 1.2.56) hizo al respecto y que terminó proverbializándose: Semper avarus eget ('El avaro siempre está necesitado') (vid. Jiménez, Morillas \& Morillo 2012: 282-284). Por otro lado, en Epicuro encontramos la misma idea: "La pobreza, medida según el rasero del fin asignado a nuestro ser, es una riqueza enorme, y una riqueza no limitada es una pobreza enorme" (SV 25; Vara 1999: 100).
} 
escasez (Oyarzún 1999: 419). Sin embargo, como hemos mencionado, la moderación será preferible en ambos casos y será esencial para la consecución de la felicidad. A este respecto, Epicuro considera que "La riqueza exigida por la Naturaleza es limitada y fácil de procurar, pero la exigida por presunciones alocadas se dispara hasta el infinito" ( $M C$ 15; Vara 1999: 95). Surge aquí la idea de la autosuficiencia, compartida por estoicos y epicúreos (Cardona 2015: 67), entendida como "la posibilidad y la capacidad de concurrir sobre la base de los propios medios a la satisfacción de lo que es necesario para la vida y su plenitud" (Oyarzún 1999: 419).

Esta moderación de la ambición para vivir de acuerdo con los límites de la vida $^{10}$ hace que el ser humano se acostumbre a vivir con lo estrictamente necesario, adecuando sus deseos a la naturaleza ${ }^{11}$. En este sentido hay que entender esta frase proverbializada de Séneca (Ep. 198.11): Quod vult habet qui velle quod satis est potest ('Tiene lo que desea quien es capaz de desear lo que le basta'), que se incluye apócrifamente entre las sentencias de Publilio Siro (Ps.Pub. 322) y se corresponde con Is minimo eget mortalis, qui minimum cupit ('El hombre que menos desea, menos necesita', I56). En este caso, más que enfocarse en la ausencia de necesidad (Nada necesita quien tiene lo bastante, 59624; Quien mucho tiene, mucho gasta; y quien poco tiene, poco le basta, 55862), los refranes españoles se centran en la limitación del deseo (No es rico el que más tiene, sino el que menos quiere, 741; No hay quien más rico sea que el que serlo no desea, 742; cf. 731-744), en alabar a quien se conforma con lo que tiene según el tópico vivere parvo ${ }^{12}$ (Ese es rico de vero, que con lo suyo está contento, 717; Hace buena cuenta quien con lo suyo se contenta, 721, cf. 717-726; La mayor riqueza es la voluntad contenta, 56119; Rico eres de bienes, si te bastan los que tienes, 746; Pobrete y alegrete, más parece riquete, 51088$)^{13}$ y denigrar a quien se deja llevar por el afán de posesiones (Quien más desea, pobre es por rico que sea, 33910; Por más rico que sea, pobre es quien algo desea, 2671; No es pobre el que tiene poco, sino el que codicia mucho, 11203), de modo que la moderación y la templanza se establecen como ideales de vida ( $E l$ vivir templadamente hace rica [a] mucha gente, 41935; Goza con tu poco, mientras busca más el loco, 731; Ni me tengo en nada, ni me falta nada, y vivo vida descansada, 757; Quien con poco se contenta, es hombre de buena cuenta, 726; Con lo

\footnotetext{
${ }^{10}$ Téngase en cuenta otra de las máximas de Epicuro: "Quien conoce los límites impuestos a la vida sabe que es fácil de procurar lo que elimina el dolor producido por falta de algo y lo que hace perfecta la vida. De modo que no necesita en absoluto tareas que entrañan competencias" (MC 21; Vara 1999: 95).

${ }^{11}$ Los estoicos elaboran una filosofia para aprender qué hay que desear y qué hay que evitar, llegando a la conclusión de que solo hay que desear lo que sea realista de acuerdo con el orden cósmico (Sellars 2006: 51).

${ }^{12}$ Sobre el tópico, vid. Jiménez, Morillas \& Morillo (2012: 160, 310-311, 630).

${ }^{13}$ Entre otras fuentes, encontramos la misma idea en un tratado sobre el estoicismo escrito por Cicerón (Parad. Stoic. 6.3.51): "contentum (...) suis rebus esse, maxime sunt certissimaeque divitiae" ('estar contento con lo propio, es la mayor y más segura de las riquezas').
} 
poco que tengo me entretengo, y voy y vengo, 736; Disfruta bien lo que tienes y no ansies muchos bienes, 738; Por rico se tiene el que con su pobreza se aviene, $744^{14}$ ).

Por consiguiente, todo lo que vaya más allá de las necesidades naturales se juzgará negativamente, ya que se concebirá como una pasión que perturbará el ánimo y lo llenará de temor a perderlo, siendo el miedo uno de los grandes escollos que impiden alcanzar la felicidad, tanto desde el punto de vista estoico como epicúreo (Cardona 2015: 108-109). En este contexto puede explicarse la sentencia Quidquid plus quam necesse est possideas, permit ('Todo lo que poseas más de lo necesario es una carga', Q51): o por el miedo a perderlo, o por impedir el propio desarrollo personal. En español encontramos paremias que asocian la riqueza con las preocupaciones por perderla ${ }^{15}$ (Más teme quien más tiene, 56088; El codicioso no goza reposo, 11261; A más oro, menos reposo, 18501; El acaudalado nunca vive sosegado, 56092; Riquezas con sobresaltos, miserias las llamo, 56097; Gran riqueza, cien quebraderos de cabeza, 56104), lo cual se opone a la tranquilidad de ánimo del que vive sin ella (Quien no tiene, no teme, 50981; Quien menos tiene, mejor duerme, 50985; Hijos y dineros, menos cuidados cuando son menos, 30600). En consonancia, algunas paremias ponen énfasis en la conveniencia de lo indispensable (Lo que basta, nunca es poco, 59619; Lo que basta vale más que lo que basta y sobra, 59621; Lo bastante, más que lo mucho vale, 59618; Quien tiene lo que le basta, no diga que algo le falta, 59625; Lo que me basta, bien me abasta, 59620; Bueno es lo bastante, y malo lo sobrante, 58603; cf. 58600-58602) ${ }^{16}$, mientras otras alaban las virtudes de la escasez y denigran el perjuicio que supone la abundancia (Lo poco es mucho, 59626; Lo poco es gracia; lo mucho es carga, 23482; Lo poco agrada, y lo mucho enfada, 23479; cf. 23476-23483).

\section{CONSIDERACIONES FINALES}

Como hemos podido ver a lo largo de estas páginas, el refranero español se nutre de la tradición clásica en la que se inscriben las Sententiae de Publilio Siro. En cuanto al tema de la avaricia, los aspectos menos productivos son aquellos que se

\footnotetext{
${ }^{14}$ Este último refrán se corresponde casi literalmente con Cui cum paupertate bene convenit, dives est ('Quien se aviene bien con la pobreza, es rico', Sen. Ep. 4.11; cf. Ps.Pub. 84).

${ }^{15}$ En la línea de la frase proverbializada Misera est magni custodia census ('La custodia de una gran riqueza es angustiosa', Juv. 14.304) y de otra sentencia de Siro: Bona quae veniunt, nisi sustineantur, opprimunt ('Los bienes que nos vienen, si no se saben mantener, nos oprimen', B26).

${ }^{16}$ A pesar de que esta es la ideología dominante en el refranero, hallamos también alguna paremia discordante (Si no sobra, no hay bastante, 58587; Asaz no hay si sobrado no hay, 58588). Estas discrepancias son algo habitual en el refranero, el cual en ocasiones contiene refranes contrarios que, a nuestro modo de ver, son una muestra de que no reflejan verdades universales, sino creencias parciales en torno a la realidad y a la forma de conducirse en la sociedad.
} 
centran en la propia naturaleza del avaro, mientras que el refranero se detiene en crear numerosas variaciones de las sentencias que presentan una índole más práctica: cómo afecta a los otros o cómo hay que comportarse para evitar caer en la avaricia. Esta desigualdad pone de manifiesto que numerosos refranes se usan con clara voluntad de guiar la conducta, ya sea presentando de forma axiológica creencias a las que se les da aire de universalidad para que sean aceptadas como tal, ya sea de forma preceptiva instando al interlocutor a actuar de una forma determinada ${ }^{17}$.

Más allá de las preferencias del refranero por unos u otros aspectos, en la adaptación al español de las Sententiae a menudo se hace evidente una alteración de la solemnidad con la que el tema de la avaricia es tratado por las paremias latinas y la filosofía helenística, dado que la crítica de la avaricia se adapta al carácter festivo y popular del refranero, tiñéndose de una jocosidad generalmente ausente en las Sententiae de Siro. Sin duda en esto es decisivo el hecho de que unas paremias pertenezcan a la tradición culta (escrita) y las otras a la popular (oral).

\footnotetext{
${ }^{17}$ Como ejemplos sirvan dos refranes citados: Por rico se tiene el que con su pobreza se aviene (axiológico), Disfruta bien lo que tienes y no ansíes muchos bienes (preceptivo).
} 


\section{BIBLIOGRAFÍA}

Cardona, J.A. (2015). Filosofia helenistica. Estoicos, epicúreos, cínicos y escépticos. Barcelona: Batiscafo.

Corpas Pastor, G. (1996). Manual de fraseología española. Madrid: Gredos.

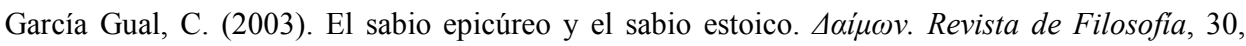
23-31.

Giancotti, F. (1963). Ricerche sulla tradizioine manoscrita delle sentenze di Publilio Siro. Messina-Firenze: Biblioteca di Cultura Contemporanea.

Jiménez Gazapo, P., Morillas Gómez, M. \& Morillo Ruiz, F. (2012). La Musa sensata. Aforismos y proverbios en la sátira latina. Madrid: Cátedra.

Long, A. (2005 [1984]). La Filosofía helenística: estoicos, epicúreos, escépticos. Versión española de P. Jordán de Urries. Madrid: Alianza.

Martínez Kleiser, L. (1953). Refranero general ideológico español. Madrid: Hernando.

Martos Montiel, J.F. (1998). El concepto de placer en la ética estoica. Florentia Iliberritana, 9, 199-213.

Meyer, W. (ed.) (1880). Publilii Syri Mimi sententiae. Leipzig: Teubner.

Oyarzún, P. (1999). Epicuro. Carta a Meneceo. Noticia, traducción y notas. Onomazein. Revista de lingüistica, filología y traducción, 4, 403-425.

Round, N.G. (1972). The Mediaeval Reputation of the Proverbia Senecae. A Partial Survey Based On Recordad MSS. Proceedings of the Royal Irish Academy. Archaeology, Culture, History, Literature, 72, 103-151.

Sánchez Doncel, G. (2003). Diccionario de latinismos y frases latinas. Madrid: Noesis.

Sbarbi, J.M. (1943). Gran diccionario de refranes de la lengua española. Buenos Aires: Joaquín Gil.

Sellars, J. (2006). Stoicism (Ancient Philosophies). Durham: Acumen Publishing.

Sevilla, J. \& Cantera, J. (2002). Pocas palabras bastan. Vida e interculturalidad del refrán. Salamanca: Diputación de Salamanca.

Sorabji, R. (2000). Emotion and Peace of Mind. From Stoic Agitation to Christian Temptation. Oxford: Oxford University Press.

Vara, J. (ed. y trad.) (1999). Epicuro. Obras completas. Madrid: Cátedra. 